\title{
Spiritual Needs of the Muslim Elderly Living in Nursing Homes: A Qualitative Study
}

\author{
Ali Jadidi ${ }^{1} \cdot$ Efat Sadeghian $^{2} \cdot$ Masoud Khodaveisi $^{3}$. \\ Masoud Fallahi-Khoshknab ${ }^{4}$
}

Accepted: 12 April 2021 / Published online: 29 April 2021

(C) The Author(s), under exclusive licence to Springer Science+Business Media, LLC, part of Springer Nature 2021

\begin{abstract}
Paying attention to and meeting the needs of people who are elderly helps to improve their health. Caring for the elderly includes addressing their spiritual needs which has been less investigated. This study aimed to examine the spiritual needs of the Muslim elderly living in nursing homes. A qualitative study was conducted using conventional content analysis. Seventeen elderly people (nine women and eight men) were selected from four nursing homes in Iran using purposive sampling. The subjects were asked to participate in semi-structured interviews. The interview transcripts were analyzed using content analysis. First, semantic units were identified and then related codes were extracted and classified into categories and subcategories based on their similarities. Finally, themes were extracted from the data. The elderly's spiritual needs were classified into three main themes: religious needs, existential needs, and communication needs. Religious needs were divided into religious beliefs, individual religious practices, and collective religious practices. Existential needs were categorized as meaning of life, purpose of life, and need for peace. Communication needs were conceptualized to include relationship with God and relationship with others. It is argued that caregivers of the elderly should recognize the elderly's spiritual needs, including religious, existential, and communication needs, and attempt to maintain and promote the elderly's spiritual health.
\end{abstract}

Keywords Aged $\cdot$ Spirituality $\cdot$ Geriatric nursing

Masoud Khodaveisi

khodaveisi@umsha.ac.ir; khodaviesimasoud@yahoo.com

Extended author information available on the last page of the article 


\section{Introduction}

Old age is a critical phase in human life, during which people face potential threats such as increased risk of chronic diseases, loneliness, and lack of social support. Therefore, paying attention to people's issues and needs during this stage of life is a social necessity (Minarti \& Kastubi, 2019). Among people at this life stage, the elderly living in nursing homes need to receive more attention as they are deprived of family support and thus are more vulnerable (Xs et al., 2018; Khodaveisi et al., 2018).

Older people have spiritual needs in addition to their multiple physical and mental needs. Addressing spiritual needs is a major part of caring for the elderly. Spiritual needs can influence the elderly's health and quality of life (ZadwornaCieślak, 2019). Spirituality is not confined to a particular religion and often includes a sense of transcendence beyond one's immediate circumstances and other dimensions such as meaning and purpose in life, reliance on inner resources, and a sense of within-person integration or connectedness (Mukherjee, 2016). Spiritual needs refer to needs associated with attitudes, values, and hopes that connect an individual to a superior being and lead to health benefits, wellbeing, and life improvement (Barton, 2020).

However, studies are limited on the elderly's spiritual needs. One reason is that healthcare providers may not be able to recognize such needs (Peteet et al., 2019). Understanding and meeting the elderly's spiritual needs can act as an adjustment mechanism for nurses and help them provide more effective care. Although some studies have examined the elderly's spiritual needs, they have not completely explained the nature of such needs (Chen et al., 2017).

Desmet et al. (2020) believe that spirituality is a major challenge in old age, and that unresolved ambiguities and questions related to spirituality can cause spiritual distress in the elderly (Desmet et al., 2020). Weng et al. (2020) believe that nurses should consider their clients as spiritual beings and recognize their spiritual needs, although it may sometimes be annoying, while performing medical services (Weng et al., 2020). In their study, McDonald et al. (2018) observed that spiritual needs of the elderly living in residential/nursing homes were not fully met, which reduced the quality of care provided to them (McDonald et al., 2018). Similarly, Erichsen and Büssing (2013) in their study on 100 elderly people living in nursing homes revealed that meeting the elderly's spiritual needs was critical in promoting life satisfaction among them (Erichsen \& Büssing, 2013).

Sivertsen et al. (2019) reported that healthcare protocols should be modified and performed according to the cultural, religious, and spiritual conditions of society and the elderly to promote the quality of care provided to the elderly and increase satisfaction among them and among healthcare providers (Sivertsen et al., 2019). The elderly need to see and understand meaning and purpose in life and to seek enhanced spiritual development. Healthcare providers are responsible to make the situation appropriate for spiritual development. If the elderly attend to their spirituality, they may understand the meaning and purpose of their lives and report greater life satisfaction (Bester et al., 2016). 
However, the nature of spiritual needs in nursing home residents is still unclear, and there is insufficient knowledge about spiritual needs of older people living in long-term care centers. Therefore, this study mainly aimed to examine spiritual needs of Muslim elderly people living in nursing homes and determine the nature of such needs by conducting an in-depth qualitative analysis of the elderly's practical experiences in this regard.

\section{Methodology}

\section{Design}

A qualitative study was conducted using conventional content analysis. In content analysis, a deeper or more meaningful understanding of human experiences can be achieved (Peterson, 2019).

\section{Participants}

Participants in the study were selected from the elderly living in four nursing homes in the city of Arak, Iran, through purposive sampling, and 17 elderly people (nine women and eight men) were enrolled in the study. The inclusion criteria were permanent residence in nursing homes, age above 60 years, absence of any critical diseases such as cancer and kidney failure, and cooperation with the researchers. The participants were demographically diverse regarding age, sex, education level, and duration of residence in nursing homes to increase the richness of data.

\section{Data Collection}

The study was conducted from January to November 2020. The main data collection tool was individual semi-structured interviews, and field notes were also employed. The interviews were performed in a quiet place in the nursing homes, starting with general, open-ended questions, such as "What does come to your mind by the phrase "spiritual needs"? or "What do you know about spirituality?" Based on the participants' responses, they were asked to provide further clarification with phrases and questions, such as "Please explain more" and "What do you mean?" At the end of each interview, the participants were encouraged to provide more explanations by asking them questions, such as "Is there anything that you want to say?" Given the participants' responses and by considering the main research question, each interview was followed individually. Data collection continued until data saturation point. Accordingly, data saturation was obtained and the first category was formed after 14 interviews. Subsequent interviews were conducted, but data analysis yielded similar results and confirmed the emerging themes. Each interview lasted 43-58 min (49 min on average). All the interviews were recorded after obtaining written consent from the participants. 


\section{Data Analysis}

Content analysis was applied to analyze the data. To this end, the interviews were transcribed, the transcripts were carefully read and compared with the notes, and semantic units were identified. Afterward, related codes were extracted, labeled, and put in specific subcategories based on their similarities and the subjectivity level. The subcategories were then classified into categories and, finally, themes were identified. MAXQDA software version 2010 was used for the data analysis.

\section{Rigor}

Lincoln and Guba (1985) suggested four criteria to confirm the credibility and robustness of qualitative data (Peterson, 2019). In this study, the credibility of the collected data was confirmed through long-term involvement with the data, the in-depth analysis of the data, combination of information sources, and employment of multiple data collection methods, such as interviews, field notes, colleague review, and participant review.

The researcher asked two individuals with similar demographics to the study population to confirm the obtained information to ascertain the transferability of the findings. The researcher carefully recorded and reported the study process and the path of decisions and provided the possibility of any follow-up for others to ensure the confirmability of the findings. The researcher employed two external observers (two nursing instructors form the Faculty of Nursing, the Hamadan University of Medical Sciences) to determine any similarities or differences in interpreting the data to evaluate the consistency of the findings.

\section{Ethical Considerations}

The researcher began the study after receiving a certificate of ethics approval with the code IR.UMSHA.REC.1398.873 and an introduction letter for the interview issued by the Research Ethics Committee of the Hamadan University of Medical Sciences. Additionally, the participants were assured of information confidentiality, and written consents were obtained from them for study participation and interview recording.

\section{Findings}

Seventeen elderly people, including nine women and eight men, with the mean age of $75.14 \pm 5.68$ years participated in the study. The participants' demographics are summarized in Table 1.

After primary coding, 760 codes were extracted, and three main themes, including spiritual needs, existential needs, and communication needs, as well as seven main categories, including religious practice, religious beliefs, meaning 
Table 1 The participants' demographics Data

\begin{tabular}{lllllll}
\hline Participant & Age & Sex & Education & Marital status & Previous job & $\begin{array}{l}\text { Length of } \\
\text { residence } \\
\text { (years) }\end{array}$ \\
\hline 1 & & & & & & \\
2 & 79 & M & Illiterate & Married & Worker & 5 \\
3 & 64 & F & Diploma & Single & Driver & 1 \\
4 & 67 & M & Primary & Widower & Teacher & 4 \\
5 & 72 & F & Primary & Widower & Housewife & 3 \\
6 & 69 & F & Primary & Divorced & Housewife & 2 \\
7 & 77 & F & Illiterate & Widower & Housewife & 1 \\
8 & 84 & M & Illiterate & Married & Driver & 6 \\
9 & 68 & M & Diploma & Widower & Employee & 2 \\
10 & 79 & F & Illiterate & Widower & Housewife & 6 \\
11 & 67 & F & Primary & Widower & Housewife & 3 \\
12 & 81 & M & Primary & Widower & Shopkeeper & 4 \\
13 & 73 & F & Illiterate & divorced & Housewife & 2 \\
14 & 76 & F & Primary & Single & Housewife & 2 \\
15 & 80 & M & Illiterate & Widower & Worker & 3 \\
16 & 86 & F & Diploma & divorced & Housewife & 4 \\
17 & 78 & F & Academic & Single & Employee & 4 \\
\hline & 84 & M & Illiterate & Married & Farmer & 3 \\
\hline
\end{tabular}

of life, purpose of life, peace, relationship with God, and relationship with others, were identified through the data analysis process. The themes and categories, along with some of the participants' statements for more elaboration, are presented below (Table 2).

\section{Religious Needs}

Most of the participants highlighted religious needs, including religious beliefs and individual/collective religious practices, as part of their needs.

\section{Religious Beliefs}

In this category, belief in the existence of God, belief in prophets and Imams, belief in afterlife, and belief in post-materialist issues were introduced as subcategories. All the participants claimed to have higher inner peace if healthcare providers and nurses could accept values mentioned above. They also regarded 


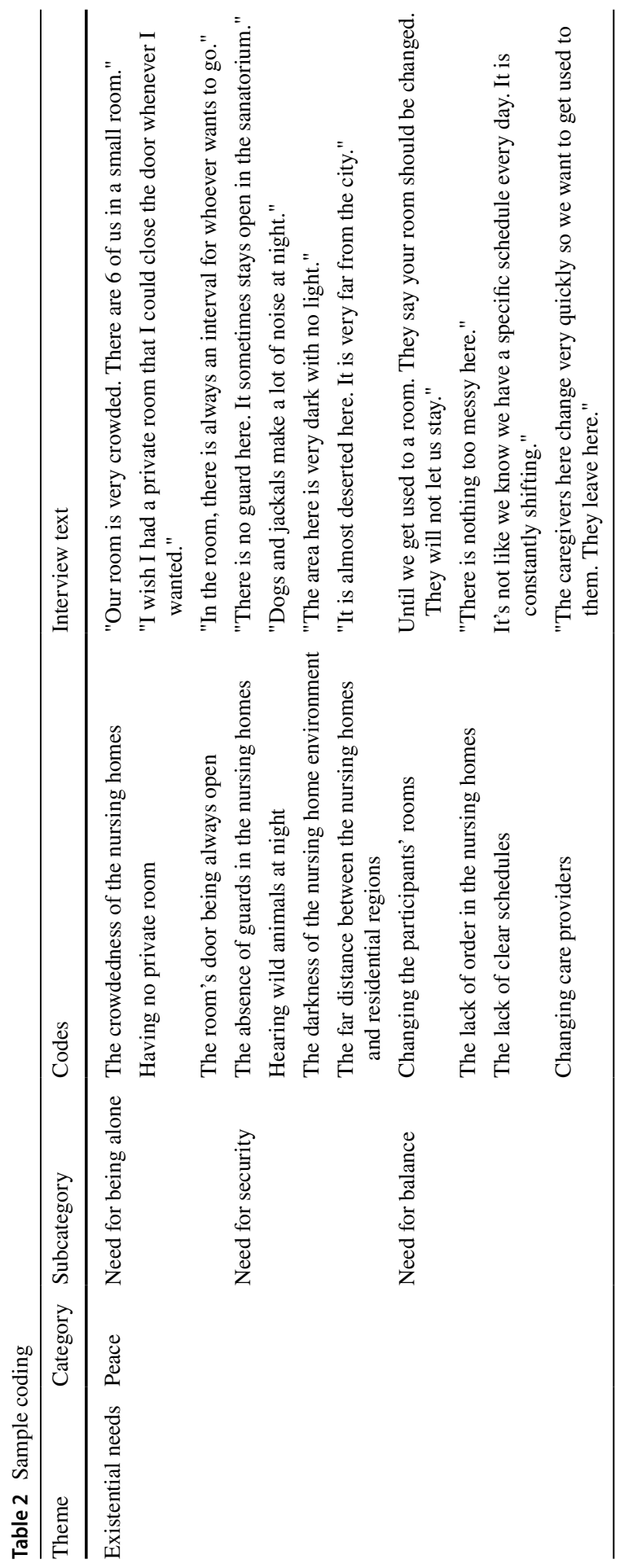


interviewing knowledgeable people on these topics as a strategy to raise awareness about these issues.

In this regard, a 79-year-old man stated: "Interest in God and religious instructions is very important to me. I like to do religious practices as much as I can. Some things that I see here are against our religious instructions. I become very upset, but I can't do anything about it" (The Participant No. 1).

Moreover, a 64-year-old woman mentioned: "I need to know more about the world after death, but no one is here to consult with" (The Participant No. 2).

\section{Individual Religious Practices}

All the participants considered performing individual religious practices as part of their spiritual needs. They also realized that as Muslims, their life meaningfulness depended on performing these practices. According to the participants, individual practices were those performed individually in homes or mosques and included fasting and I'tikaf. Fasting is performed for 1 month each year, during which individuals avoid actions like eating and drinking during the day. "I had never broken my fast, but when I came here, I couldn't fast. They said that I am old and fasting is not for me. Also, they didn't prepare Sahari and Iftar [specific meals eaten at dawn for fasting and at evening for breaking it]. I am very upset that I can't fast" (The Participant No. 9). Moreover, I'tikaf is performed by staying in a mosque for at least 3 days and praying: "In the month of Rajab, I feel like to perform I'tikaf. It feels fantastic. Many of my wishes were realized after I'tikaf. But alas! Here, the situation is not appropriate for holding this ceremony. I wish we could hold it here, too" (The Participant No. 11).

\section{Collective Religious Practices}

According to the participants, collective practices included going to Hajj, going on pilgrimage, and visiting religious places. Hajj, which is performed every year in Mecca, is one of the symbols of being a Muslim. "It was always my dream to perform Hajj with my husband, but it didn't come true, and now that I'm in nursing home, it's impossible! It would be very good if they took us old people to Hajj. But I think I should die frustrated in my wish!" (The Participant No. 4). Moreover, Muslims are mainly interested in visiting the shrines of prophets and Imams and their children. Presence in such religious places gives a special spiritual feeling to Muslims and rejoice their souls permanently. Also, many people request God to grant their needs and wants in shrines of these holy people. "Visiting the graves of prophets and Imams and their children is very important to me. Pilgrimage gives you a sense of calmness. But it doesn't matter how much we request to take us to a pilgrimage; they don't listen!" (The Participant No. 7). 


\section{Existential Needs}

Almost all the participants claimed to have existential needs, including meaning of life, purpose of life, and peace.

\section{Meaning of Life}

From the perspective of the elderly participating in the study, this concept was the most critical part of spiritual health and included life satisfaction, happiness and joy, independence, self-esteem, and dignity. The participants viewed life as meaningless if they were not satisfied with it: "If you are not satisfied with your life, you'd better to die. I don't mean that everything should be as you want, but you be somehow happy with your life, with your place of residence, friends, people around you, food, etc. These are the things which should exist in order for life to be as you want" (The Participant No. 8). According to the participants, although life has many highs and lows and joy and sorrow are inseparable, happiness and joy are necessary for living a meaningful life and maintaining hope: "I am generally a happy person. I always laugh at my problems. I take everything easy. This is why I'm not that much old. Here, I try to be happy as well and don't struggle with problems much. I think if you are not happy, you can't enjoy your life" (The Participant No. 6). One of the participants referred to recreational programs and stated: "Here, we don't have many recreational programs. We, like all people, need to be happy and joyful, otherwise we become upset and depressed" (The Participant No. 11).

Another issue emphasized by the participants was maintaining individual independence. For example, one of the participants expressed: "I think if you become old to be a burden on others' shoulders, to be fed and looked after, you're better to be dead! I like to do all my works myself. Of course, I consult with others, but I don't like my children or others to interfere with my life" (The Participant No. 13). The participants emphasized the significance of preserving dignity in old age and receiving respect from others. One of the participants mentioned: "When you get old, you are sensitive and easily irritated. The young should respect the elderly more, so that they don't feel being inferior. I don't mean that anything that the elderly say, others should do, but children should treat them respectfully in order not to upset them" (The Participant No. 11). Further, the participants highlighted the self-esteem concept and requested healthcare providers to help them preserve their self-esteem and dignity. One of the participants stated: "Care providers and nurses shouldn't treat us in a way that we feel inferior. They should try to respect our self-esteem. We are old and need to be loved by others. Our dignity should be observed. They shouldn't see us as inferiors" (The Participant No. 5).

\section{Purpose of Life}

Another spiritual need of the participants was to have purpose in life. One of the topics in this category was hopefulness. Their hopefulness was in part related to the material dimension of life and also to mental and spiritual dimensions. One of the 
participants stated: "It is true that the elderly are to kick the bucket, but they hope to end their life happily. They like to see their children and grandchildren, who are the result of their lives" (The Participant No. 10). Another one of the participants mentioned happiness in afterlife and stated: "I have always hoped in God and I still hope. God has always helped me in hard situations. Now as well, I hope that God treats us with forgiveness and forgive our sins and let us die innocent. God has promised us the Heaven and we live by the hope of the happiness in afterlife" (The Participant No. 12).

The participants highlighted future orientation as another issue. According to them, elderly people often feel vulnerable and need to live by looking into the future. One of the participants stated: "Everybody thinks that when you get old, you should always think about the past and leave the future, but as long as you are alive, you should think of the future. You should plan for your future, you should manage your income and expenses" (The Participant No. 4). Future orientation is not specific to life in this world. In Islam, belief in afterlife is one of the fundamental principles, and each Muslim plans for the future based on belief in life after death: "We have in our religious instructions that a clever and future-oriented person is one who tries for his afterlife, the one who sends good actions for his afterlife" (The Participant No. 9).

\section{Peace}

One of the fundamental needs in old age from the elderly's perspective was the need for peace. The participants stated that older people had a low capacity to cope with life challenges and tensions. The participants believed that a peaceful life was a prerequisite for fulfilling spiritual needs. They believed that nursing homes often did not provide a peaceful environment. The participants reported that despite their need to be with others, they needed to be some time alone every day: "I am very happy with the care provided here. They care about us very much. But sometimes, I need to be alone and feel peace. I need to think and have peace, but here is always crowded" (The Participant No. 7). "I wish I could be alone sometimes. You need peace and quietness. I want to be at ease in my room when I want to do a personal work, but it is not possible" (The Participant No. 11).

The participants were also concerned about security as another major issue. Financial, life, and emotional security were among the topics mentioned in the interviews. One of the participants stated: "Here, there is no guards. The gate is often left open. Some nights I hear the sounds of dogs and wild animals, I'm very frightened. Sometimes I can't sleep because of fear" (The Participant No. 14). Although all humans need to feel safe, it appears that old women are in a greater need for a secure life. Losing their husbands together with their reduced physical and mental abilities causes old women to be terrified at certain times. Thus, they need to fulfill their security needs to overcome such fears. "At nights, here is very quiet. Nurses and caregivers are asleep at their own rooms, but some of us, like me, are very frightened of the darkness here. I'm afraid that somebody comes from outside and hurts me" (The Participant No. 11). 
Stability and balance were two other concepts emphasized by the participants. They believed that older people needed to maintain stability and balance in life. Changes that bring joy and variety into the youth's life sometimes bother the elderly. The participants tended to maintain their routine life with least changes and most stability: "I was in the opposite room for a while. I got accustomed to it. Now, it is a while that they have changed my room. I'm so mad. My stuff are scattered and I should search a lot to find them" (The Participant No. 8). Another one of the participants stated: "Before, the order was better here. Everything was done on its own time. Now this is not so. They serve the lunch sometimes late, sometimes soon. This way, your schedule is always disturbed" (The Participant No. 10).

\section{Communication Needs}

The participants believed that human beings, as open systems and social beings, were inevitably connected to others. They also believed that older people needed to communicate with others to preserve and promote their spiritual health, and that such a communication need could be fulfilled by making relationships with God and others.

\section{Relationship with God}

The participants believed that from the religion's point of view, the most significant part of spiritual health was the relationship with God. They also pointed out that this relationship existed in other cultures and religions with a superior creature. However, according to them, the most elegant symbol of spiritual health for humans is the relationship with God. They stated that there was great emphasis in Islam on the relationship with God as it was the main purpose of many religious and spiritual practices, such as saying prayers, praying, and reciting Quran. The participants were concerned about the absence of any suitable place for saying prayers: "I always said my prayers at mosque or collectively with others, but there is no mosque, no collective prayers and no appropriate place for saying prayers here. This way, I'm very distressed that I can't say prayers" (The Participant No. 3). Another one of the participants highlighted the relationship with God through reciting Quran and stated: "I read the whole Quran several times each year. Quran calms me a lot. It lightens my heart. I wish I had a Quran with a large font here. There isn't even a radio to listen to Quran" (The Participant No. 13).

\section{Relationship with Others}

The relationship with others was another aspect of spiritual health from the participants' perspective. They believed that the relationship with others included relationships with relatives, friends, healthcare providers, nurses, and other people. They also believed that the relationship with others could take various forms, such as 
interacting with others, falling in love, expressing sympathy, and receiving support. In this regard, one of the participants highlighted the need for loving and stated: "I'm a mother. It doesn't matter how old my children are, they are still my children. When I see them, I like to hug and kiss them. I love my grandchildren even more than my children. But they don't visit me a lot and I can't go and visit them" (The Participant No. 1). Another one of the participants expressed: "It is true that we are old, but we need, like little children or even more than them, to be loved by our children. We need them to care about us. Of course, love is not enough; they should visit us and express their love. But they rarely visit us; they have almost forgotten us" (The Participant No. 6). Yet, one other participant mentioned the need for sympathy and stated: "I like to have a person to talk to. I don't want them to do something for me, I want them to just listen to me. This makes me relieved. I become relaxed. I have no spouse and children to talk to. When I don't talk to someone for a while, I feel something blocks my throat and I feel as if I can't breathe; but as soon as somebody comes and I talk to them a bit, I feel relieved" (The Participant No. 2).

\section{Discussion}

The study's results showed that the spiritual needs of the elderly living in nursing homes were categorized into three main themes, including religious needs, existential needs, and communication needs. Religious needs were divided into religious beliefs, individual religious practices, and collective religious practices. Existential needs were categorized as meaning of life, purpose of life, and need for peace. Communication needs were conceptualized to include relationship with God and relationship with others. All the participants highlighted religious needs as a significant part of their needs. They mentioned religious beliefs, including beliefs in the existence of God, prophets, holy Quran, and afterlife. They also described religion as related to spiritual life and considered their faith and religious beliefs as the most significant part of spiritual needs. According to their statements, faith and belief mean differently for different people. However, faith as a personal philosophy is a source of energy, peace, and assurance, and believing in God takes older people from darkness into light. This finding is consistent with results of other studies (Abdelrahman et al., 2020; Jackson et al., 2016; Kulakçı-Altıntaş \& Ayaz-Alkaya, 2020). This consistency shows the significance of meeting religious needs to promote spiritual health. In fact, humans are spiritual creatures and their souls are in search of truth and the knowledge of God (De Groot \& van den Born, 2007). By meeting such needs, Islam directs humans to the right path and teaches them how to reach their goals by picturing a superior purpose.

Moreover, the participants performed individual religious practices, such as fasting and I'tikaf, and collective religious practices, such as going to Hajj, going on pilgrimage, and visiting other religious places such as mosques, with the aim of searching for God. Searching for God through praying has a major role in improving humans' quality of life and helping them meet their spiritual needs and enhance their spiritual health. This finding is consistent with the results of Brandt et al.'s study (2019), as they believed that religious practices, such as praying, helped people 
relate with their spirituality (Brandt et al., 2019). Further, Timmins and Caldeira (2017) showed that preparing a situation to perform religious practices played a significant role in promoting individuals' spiritual health (Timmins \& Caldeira, 2017). The consistency of the results indicates that theology is the basis of all religions and cultural differences have no considerable effect on it. Going to mosques and religious places can provide the chance to communicate with others, where people feel security and sense of belonging (Momeni \& Rafiee, 2018).

Another main theme emphasized by the participants was existential needs. Recent studies have emphasized that without meaning and purpose in life, spiritual health will not be achieved and life becomes extremely painful. This study's results are consistent with those of other studies, as they reported searching for meaning and purpose in life as the most significant indicator of existential health (Byun et al., 2017; Sytsma et al., 2018; Zhang et al., 2019). Moreover, identifying purpose and meaning in life is a central part of spirituality in the holistic nursing theory approach, which shows the wholeness of people and their relationship with a superior power (Mukherjee, 2016).

Another existential need emphasized by all the participants was the need for peace. Similarly, Erichsen and Büssing (2013) found in their study that one of the spiritual needs of older people living in nursing homes was the need for inner peace, including dwelling in quiet and peaceful places, enjoying the beauty of nature, finding inner peace, and talking with others about fears and worries. They also indicated that the elderly's inner peace could be best predicted by religious values (Erichsen \& Büssing, 2013).

Another major theme emerging from the interviews was communication needs, including relationships with God and others. Most studies on spiritual health consider relationships with God, self, and others as three determining components of spiritual health. The relationship with God is a major dimension of the relationship among older people, which is expressed in the forms of saying prayers, praying, and reading religious books. The present study's results are consistent with those of Jackson et al.'s study (2016), who considered the relationship with God as a spiritual need in elderly patients (Jackson et al., 2016). Moreover, Pramesona and Taneepanichskul (2018) showed that participants did not feel comfortable to talk about life issues and concerns with others without the relationship with God (Pramesona \& Taneepanichskul, 2018).

Another aspect of this theme, as emphasized by the participants, was having a constructive and healthy relationship with others. This relationship leads to preserving and improving spiritual health and to better understanding meaning and purpose in life. Rumakey believes that the relationship with others is highly emphasized by the elderly. He also believes that those with a higher level of spiritual health have the most constructive relationship with others and use this capacity for self-transcendence and better adjustment with challenges (Rumakey et al., 2020). Similarly, in their study aiming to design a model for the elderly's spiritual needs, Monod et al. (2010) suggested a constructive relationship with others as a major component of this model. Spiritual health cannot be fully achieved in isolation and loneliness; the relationship with others is one of the necessary needs of humans, especially older people, that can disturb self-transcendence and understanding of meaning and 
purpose in life if not satisfied (Monod et al., 2010). Therefore, helping older people have a constructive relationship with each other is among their necessary needs.

\section{Conclusion}

According to the current study's results, the elderly's spiritual needs were categorized into three main themes, including religious needs, existential needs, and communication needs. Given the significance of the spiritual dimension of health, especially in the elderly, it is of paramount importance to know their spiritual needs. Therefore, considering this study's results, healthcare providers should pay attention to older people's spiritual needs and take actions to cover such needs to the extent possible to promote their spiritual health.

\section{Limitations}

The study population only included the Muslim elderly without any serious disease living in nursing homes. It is recommended to study spiritual needs in older people of other religions with physical and mental diseases living in homes. Moreover, this study was conducted in part during the coronavirus disease-2019 outbreak, which may have interfered with the study's results due to the restricted access to people and fear and anxiety caused by the disease pandemic.

Acknowledgements This study was part of a PhD dissertation in Nursing at the Hamadan University of Medical Sciences. The researcher would like to thank all the dear participants, care providers, and nurses at the nursing homes and also the authorities of the Hamadan University of Medical Sciences.

Author Contributions AJ: Designing and conducting the research, analyzing the data and writing the article. MK: Contributing to designing and conducting the research and analyzing the data. ES: Contributing to designing and conducting the research, analyzing the data and writing the article. MFK Contributing to designing and conducting the research, analyzing the data and submitting the article.

\section{Declarations}

Conflicts of interest The authors declare that they have no conflicts of interest.

\section{References}

Abdelrahman, H., Asim, M., \& El-Menyar, A. (2020). Spiritual and religious considerations in the care of the elderly. In Surgical decision making in geriatrics (pp. 409-417). Springer, Cham.

Barton, S. (2020). Psychosocial, social, and spiritual needs of geriatric patients. In Geriatric practice (pp. bvkghkhtuy-;=uuypu;tyo=-ro-0tyrplt nmbjv gg,yft543-554). Springer, Cham.

Bester, E., Naidoo, P., \& Botha, A. (2016). The role of mindfulness in the relationship between life satisfaction and spiritual wellbeing amongst the elderly. Social Work, 52(2), 245-266 
Brandt, P. Y., Robert, Z. D., \& Laubscher, K. (2019). Spiritual care for the elderly. Studia Universitatis Babes-Bolyai Theologia Orthodoxa, 64(2), 105-114

Byun, M. K., Hyun, H. J., Park, S. J., \& Choi, E. Y. (2017). Efficacy of well-dying program for meaning of life, self-efficiency, and successive aging in the elderly. Journal of the Korea Academia-Industrial cooperation Society, 18(10), 413-422

Chen, Y. H., Lin, L. C., Chuang, L. L., \& Chen, M. L. (2017). The Relationship of physiopsychosocial factors and spiritual well-being in elderly residents: implications for evidence-based practice. Worldviews on Evidence-Based Nursing, 14(6), 484-491

DeGroot, M., \& van den Born, R. (2007). Humans, nature and god: Exploring images of their interrelationships in Victoria, Canada. Worldviews: Global Religions, Culture, Ecology, 11(3), 324-351

Desmet, L., Dezutter, J., Vandenhoeck, A., \& Dillen, A. (2020). Spiritual needs of older adults during hospitalization: an integrative review. Religions, 11(10), 529-555

Erichsen, N.-B., \& Büssing, A. (2013). Spiritual needs of elderly living in residential/nursing homes. Evidence-Based Complementary and Alternative Medicine, 20(3), 1-10

Jackson, D., Doyle, C., Capon, H., \& Pringle, E. (2016). Spirituality, spiritual need, and spiritual care in aged care: What the literature says. Journal of Religion, Spirituality \& Aging, 28(4), 281-295

Khodaveisi, M., Faal Araghi Nejad, A., Omidi, A., Esmaili Vardanjani, A., \& Tapak, L. (2018). Comparing the structural standards of nursing homes in Markazi Province, Iran with international standards. Iranian Journal of Ageing, 13(3), 362-371

Kulakçı-Altıntaş, H., \& Ayaz-Alkaya, S. (2020). Adaptation difficulty and religious coping styles for the elderly in Turkey. Psychogeriatrics, 20(6), 865-870

Lincoln, Y. S., \& Guba, E. G. (1985). Naturalistic enquirey, Beverly Hills, CA: Sage.

McDonald, P., Wykle, M., \& Hilton, G. (2018). Spiritual needs of older adults in long-term care: The nurse's role. Journal of National Black Nurses' Association: JNBNA, 29(2), 29-35

Minarti, M., \& Kastubi, K. (2019). Islamic spiritual wellbeing among elders. Aloha International Journal of Multidisciplinary Advancement (AIJMU), 1(2), 35-38

Momeni, K., \& Rafiee, Z. (2018). Correlation of social support and religious orientation with life satisfaction in the elderly. Iranian Journal of Ageing, 13(1), 50-61

Monod, S. M., Rochat, E., Büla, C. J., Jobin, G., Martin, E., \& Spencer, B. (2010). The spiritual distress assessment tool: An instrument to assess spiritual distress in hospitalised elderly persons. $B M C$ Geriatrics, 10(1), 88-96

Mukherjee, S. B. (2016). Spirituality and religion: Elderly's perception and understanding. Indian Journal of Gerontology, 30(3), 336-354

Peteet, J. R., Al Zaben, F., \& Koenig, H. G. (2019). Integrating spirituality into the care of older adults. International Psychogeriatrics, 31(1), 31-38

Peterson, J. S. (2019). Presenting a qualitative study: A reviewer's perspective. Gifted Child Quarterly, 63(3), 147-158

Pramesona, B. A., \& Taneepanichskul, S. (2018). The effect of religious intervention on depressive symptoms and quality of life among Indonesian elderly in nursing homes: A quasi-experimental study. Clinical Interventions in Aging, 13, 473-483

Rumakey, R. S., Indarwati, R., \& Andriani, M. (2020). Effect of spiritual cognitive therapy on decreasing the depression level among elderly at nursing home. International Journal of Nursing and Health Services (IJNHS), 3(3), 418-423

Sivertsen, N., Harrington, A., \& Hamiduzzaman, M. (2019). Exploring aboriginal aged care residents' cultural and spiritual needs in South Australia. BMC Health Services Research, 19(1), 477-489

Sytsma, T. T., Schmelkin, L. A., Jenkins, S. M., Lovejoy, L. A., Lapid, M. I., \& Piderman, K. M. (2018). "Keep the faith": Spirituality as a contributor to resiliency in five elderly people. Journal of Religion, Spirituality \& Aging, 30(4), 314-324

Timmins, F., \& Caldeira, S. (2017). Assessing the spiritual needs of patients. Nursing Standard, 31(29), 47-53

Weng, N., Li, K., Lan, H., Zhang, T., Zhang, X., Gui, Y., Fu, X., \& Liu, Q. (2020). Evaluation of the reliability and validity of functional assessment of chronic illness therapy-spiritual well-beingexpanded in elderly patients with chronic orthopaedic diseases. Psychogeriatrics, 21(1), 32-41 
Zadworna-Cieślak, M. (2019). Spirituality, satisfaction with life and health-related behavior of older residents of long-term care institutions-A pilot study. Explore, 16(2), 123-129

Zhang, J., Peng, J., Gao, P., Huang, H., Cao, Y., Zheng, L., \& Miao, D. (2019). Relationship between meaning in life and death anxiety in the elderly: Self-esteem as a mediator. BMC Geriatrics, 19(1), $1-8$

Publisher's Note Springer Nature remains neutral with regard to jurisdictional claims in published maps and institutional affiliations.

\section{Authors and Affiliations}

\section{Ali Jadidi ${ }^{1}$. Efat Sadeghian ${ }^{2}$. Masoud Khodaveisi ${ }^{3}$. Masoud Fallahi-Khoshknab ${ }^{4}$}

Ali Jadidi

jadidi.ali83@yahoo.com

Efat Sadeghian

sadeghianefat@gmail.com

Masoud Fallahi-Khoshknab

msflir@yahoo.com

1 School of Nursing and Midwifery, Hamadan University of Medical Sciences, Hamadan, Iran

2 Chronic Disease (Home Care) Research Center, Nursing Department, School of Nursing and Midwifery, Hamadan University of Medical Sciences, Hamadan, Iran

3 Chronic Disease (Home Care) Research Center, Community Health Nursing Department, School of Nursing and Midwifery, Hamadan University of Medical Sciences, Hamadan, Iran

4 Department of Nursing, University of Social Welfare and Rehabilitation Sciences, Tehran, Iran 